\title{
Pengendalian Kualitas Free Fatty Acid Bagian Refinery Plant Di PT X Kota Dumai
}

\author{
Suryanto $^{(1)}$, Yusrizal ${ }^{(2)}$, Noto \\ Wiroto $^{(3)}$ \\ 1,2,3) Program Studi Teknik Industri, \\ Sekolah Tinggi Teknologi Dumai \\ Jl. Utama Karya Bukit Batrem II \\ Email: \\ anto.surya1995@gmail.com; \\ yusrizalpuket2@gmail.com; \\ notowirotosttd@gmail.com
}

\begin{abstract}
ABSTRAK
Kebutuhan akan minyak nabati (kelapa sawit) semakin meningkat, hal ini diisyaratkan dengan terus bertambah dan berkembangkan perusahaan-perusahan yang mengolah minyak kelapa sawit di Indonesia terkhususnya di area kota Dumai. Oleh karena itu kualitas harus benar-benar terjaga agar produk dapat bersaing dengan baik di pasar dagang dunia. Dari uraian diatas penulis melakukan peelitian pada produk turunan dari CPO yang berupa produk RBDPO (Refined Deodorized Palm Oil), Olein dan Stearin, dimana paramameter yang penulis gunakan ialah FFA (Free Fatty Acid) dari ketiga produk turunan kelapa sawit tersebut. Berdasarkan permasalahan tersebut, penulis melakukan penelitian dengan menggunakan metode peta kendali $\overline{\mathrm{X}}$ dan R. Dengan menggunakan metode peta kendali $\overline{\mathrm{X}}$ dan $\mathrm{R}$ maka akan didapat nilai batas kendali atas nilai tengah dan nilai batas kendali bawah. Hal ini untuk mengetahui apakah sampel pada RBDPO (Refined Deodorized Palm Oil, Olein dan Stearin berada dalam batas peta kendali kontrol. Hasil dari penelitian dengan menggunakan metode $\overline{\mathrm{X}}$ dan R semua sampel RBDPO, Olein dan Stearin berada dalam batas peta kendali setelah dilakukan peta revisi sebanyak 3 kali untuk RBDPO dan Olein, 2 kali untuk produk Stearin dengan jumlah sampel yang berbeda-beda.
\end{abstract}

Kata kunci: Free Fatti Acid, Olein, Peta Kendali X dan R, RBDPO, Stearin.

\section{ABSTRACT}

The need for vegetable oil (palm oil) is increasing, this is hinted by continuing to grow and develop companies that process palm oil in Indonesia, especially in the dumai city area. Therefore, quality must be fully maintained in order for products to compete well in the world trade market. From the above description, the author did peelitian on derivative products from $\mathrm{CPO}$ in the form of RBDPO (Refined Deodorized Palm Oil), Olein and Stearin products, where the paramameter that the author uses is FFA (Free Fatty Acid) of the three palm derivative products. Based on these problems, the authors conducted the study using the control map method "X"- and R. Using the control map method " $\mathrm{X}^{-}$- and R, the limit value of control over the middle value and the lower control limit value will be obtained. This is to find out if the sample on rbdpo (refined deodorized palm oil, olein and stearin is within the limits of the control map). The results of the study using the "X"- and R methods of all RBDPO, Olein and Stearin samples were within the limit of the control map after being revised 3 times for RBDPO and Olein, 2 times for Stearin products with different sample numbers.

Kata kunci: Control Map X and R, Free Fatti Acid, Olein, RBDPO, Stearin. 


\section{Pendahuluan}

PT X merupakan salah satu perusahaan yang bergerak dibidang produksi minyak nabati kelapa sawit. Produk yang dihasilkan dari turunan kelapa sawit diantaranya RBDPO (Refined Bleach Deodorized Palm Oil), Olein dan Stearin. Setelah melalui proses refinery dan fraksinasi CPO memiliki turunan diantaranya adalah RBDPO (refined bleach deodorized palm oil), Olein (miyak goreng) dan Stearin (bahan dasar campuran margarin). Mutu adalah kesesuaian dengan spesifikasi yang ada, yang harus memenuhi keinginan pembeli spesifikasi dapat ditentukan oleh produsen atau konsumen. Berdasarkan uraian diatas penulis melakukan penelitian dengan judul "Pengendalian Kualitas FFA (Free Fatty Acid) Bagian Refineery Plant Di PT X Kota Dumai" dengan menggunakan metode peta kendali $\bar{x}$ dan $\mathrm{R}$ pemilihan metode ini lebih cocok jika digunakan untuk mengetahui kadar kualitas FFA pada RBDPO, Olein dan Stearin hal ini dikarenakan peta kendali $\bar{x}$ dan $\mathrm{R}$ memiliki batas range atas dan range bawah yang menunjukkan terkendalinya suatu produk.

\section{Metode Penelitian}

Penelitian ini dilakukan pada PT X Kota Dumai penelitian ini dilaksanakan sekama 1 bulan terhitung mulai tanggal 1 hingga 30 juni 2018. Jenis data yang penulis gunakan ialah data Variabel dengan menggunakan peta kendali $\bar{x}$ dan R. Dimana instrumen dalam penelitian ini diantaranya FFA (Free Fatty Acid) dari produk RBDPO, Olein dan Stearin. Prosedur dalam pengumpulan data ini dilakukan 3 sampel dalam 1 hari.

\section{Hasil dan Pembahasan}

Berdasarkan penelitian yang dilakukan selama 30 hari di PT X kota Dumai, dengan menggunakan metode $\overline{\mathrm{X}}$ dan $\mathrm{R}$ terdapat kadar FFA (free fatty acid) yang masih berada diluar batas peta kendali. Setelah dilakukan peta perbaikan kadar FFA untuk sampel RBDPO, Olein dan Stearin berada didalam peta kendali. Dimana penyebab dari keluarnya sampel terjadi diantarannya karena penurunan suhu pada proses kristalisasi, pengambilan sampel dilapangan dimana alat atau wadah untuk mengambil sampel tidak disterilkan tersebih dahulu, tempat penyimpanan yang berbeda antara RBDPO, Olein dan Stearin serta sterilisasi dari tanki tersebut. Langkah-langkah yang dapat diambil untuk mengendalikan kadar FFA yang outspec ialah dengan 2 (dua) cara. Cara yang pertama ialah dengan memblending (mencampurkan) minyak dengan kadar FFA yang rendah. Lalu cara kedua ialah dengan memproduksi/sirkulasi ulang produk yang outspec tersebut pada refineery (pemurnian) plant kembali. Rumus peta kontrol $\mathrm{S}$ dan $\mathrm{R}$ adalah sebagai berikut:

$\overline{\mathrm{X}}=\frac{\sum_{\mathrm{i}=1}^{\mathrm{n}} \mathrm{x}_{\mathrm{i}}}{\mathrm{n}}$ dan $\mathrm{R}=\mathrm{X} \max -\mathrm{X} \min$

Center Line $(\mathrm{CL}) \overline{\mathrm{X}}=\frac{\sum_{\mathrm{i}-1}^{\mathrm{m}} \overline{\mathrm{x}}}{\mathrm{n}}$ dan $\overline{\mathrm{R}}=\frac{\sum_{\mathrm{i}=1}^{\mathrm{m}} \mathrm{R}_{\mathrm{i}}}{\mathrm{n}}$

Upper Control Limite UCL $\overline{\mathrm{X}}=\overline{\overline{\mathrm{X}}}+\mathrm{A}_{2} \overline{\mathrm{R}}$

Lower Control Limite LCL $\overline{\mathrm{X}}=\overline{\mathrm{X}}-\mathrm{A}_{2} \overline{\mathrm{R}}$

Upper Control Limite UCL R $=\mathrm{D}_{4} \overline{\mathrm{R}}$ 
Lower Control Limite LCL $\mathrm{R}=\mathrm{D}_{3} \overline{\mathrm{R}}$

Setelah dilakukan perhitungan dengan menggunakan peta kontrol X maka grafik pengamatan $\bar{X}$ Pada RBDPO (Refined Bleach Deodorized Palm Oil) sebelum dan sesudah revisi hasilnya dapat dilihat pada Gambar 1 dan 2.

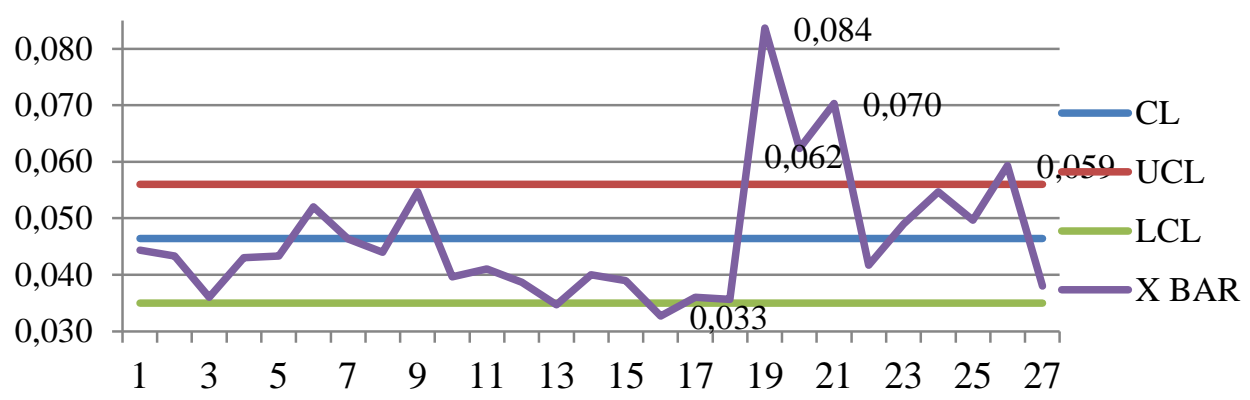

Gambar 1. Grafik Pengamatan X Pada RBDPO (Refined Bleach Deodorized Palm Oil) Sebelum Dilakukan Revisi

Sumber: Penelitian 2021

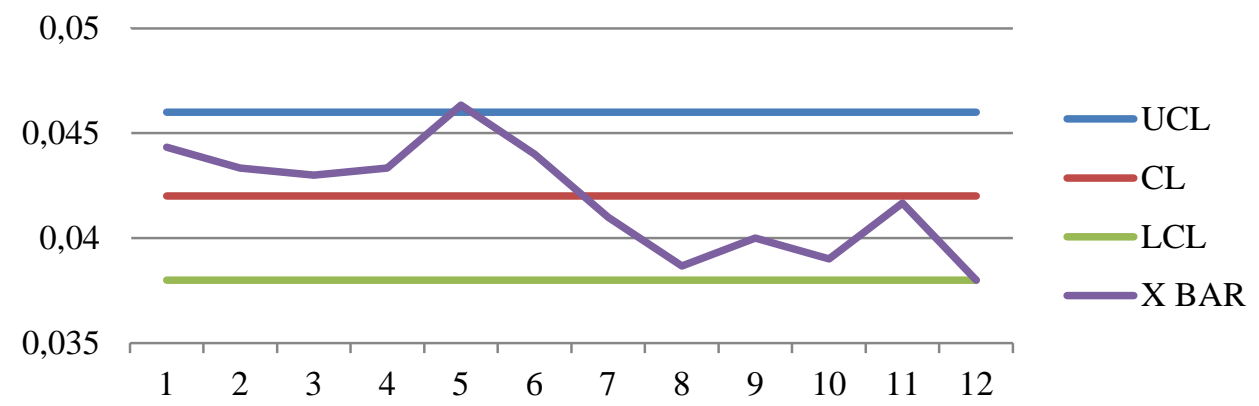

Gambar 2. Grafik Pengamatan X Pada RBDPO (Refined Bleach Deodorized Palm Oil). Setelah Dilakukan Revisi

Sumber: Penelitian 2021

Sedangkan Grafik pengamatan RBDPO sebelum dan sesudah dilakukan revisi peta $\mathrm{R}$ dapat dilihat pada Gambar 3 dan 4.

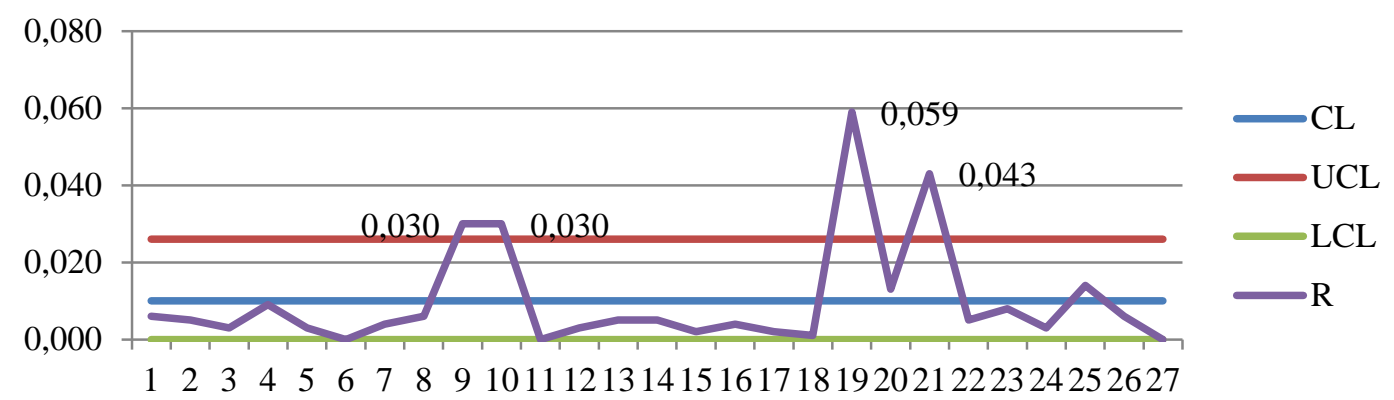

Gambar 3. Grafik Pengamatan R Pada RBDPO (Refined Bleach Deodorized Palm Oil) Sebelum Dilakukan Revisi

Sumber: Penelitian 2021 


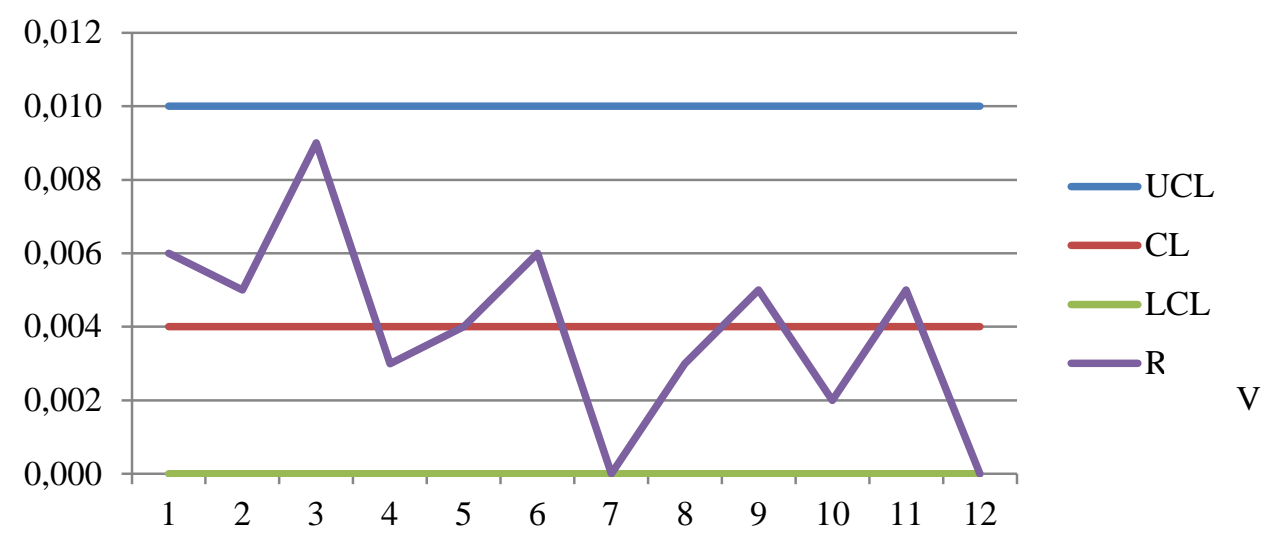

Gambar 4. Grafik Pengamatan R Pada RBDPO (Refined Bleach Deodorized Palm Oil) Setelah Dilakukan Revisi

Sumber: Penelitian 2021

Grafik Pengamatan Peta $\bar{X}$ FFA Pada Olein sebelum dan sesudah dilakukan revisi dapat dilihat pada Gambar 5 dan 6.

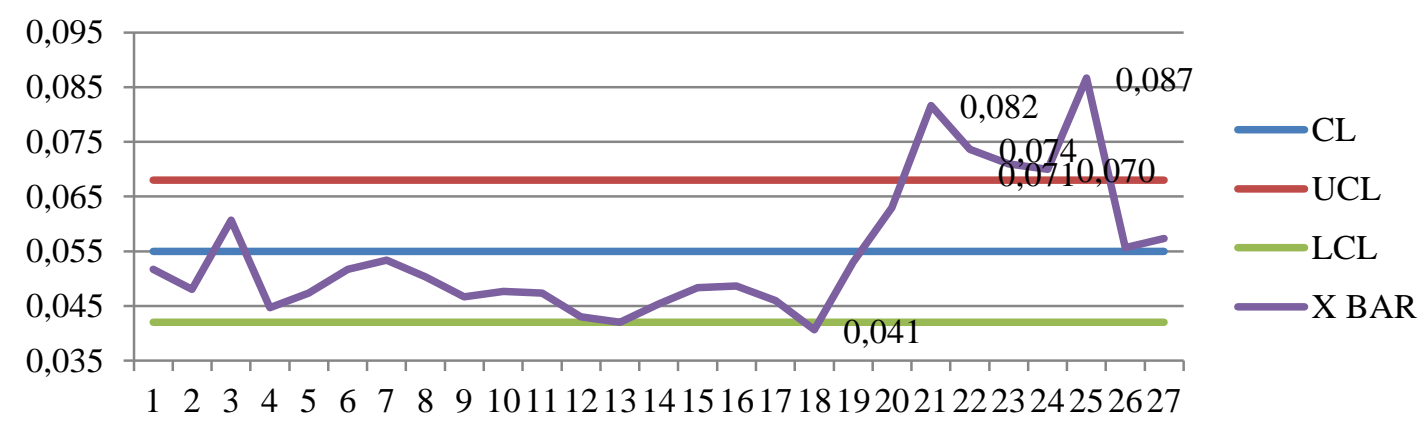

Gambar 5. Gambar Pengamatan X Pada FFA Olein Sebelum Dilakukan Revisi Sumber: Penelitian 2021

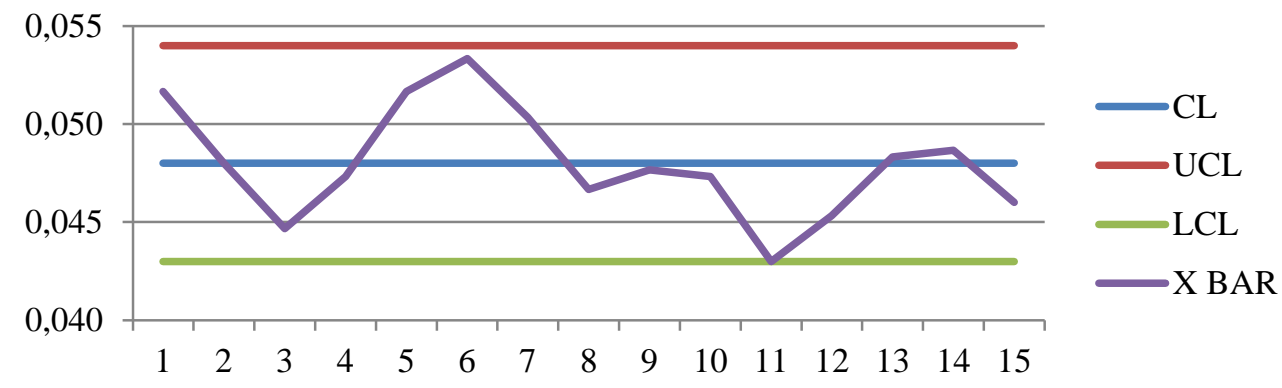

Gambar 6. Gambar Pengamatan X Pada FFA Olein Setelah Dilakukan Revisi Sumber: Penelitian 2021

Grafik Pengamatan Peta R FFA Pada Olein sebelum dan sesudah dilakukan peta revisi $\overline{\mathrm{X}}$ dapat dilihat pada Gambar 7 dan 8 . 


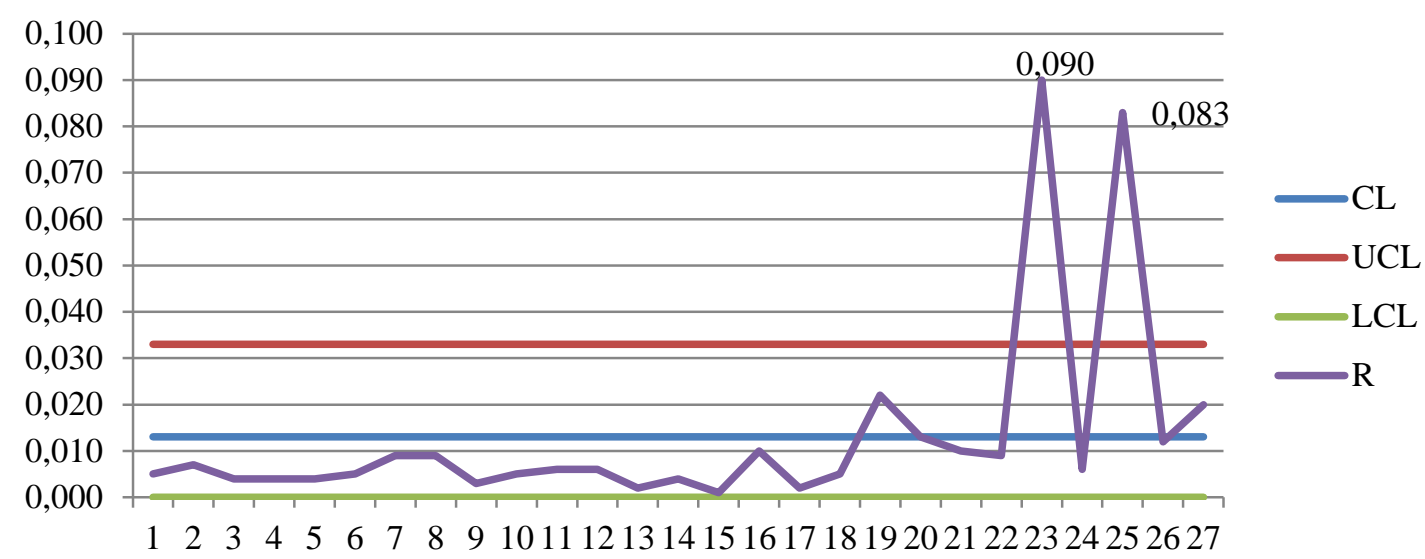

Gambar 7. Grafik Pengamatan R Pada FFA Olein Sebelum Dilakukan Revisi Sumber: Penelitian 2021

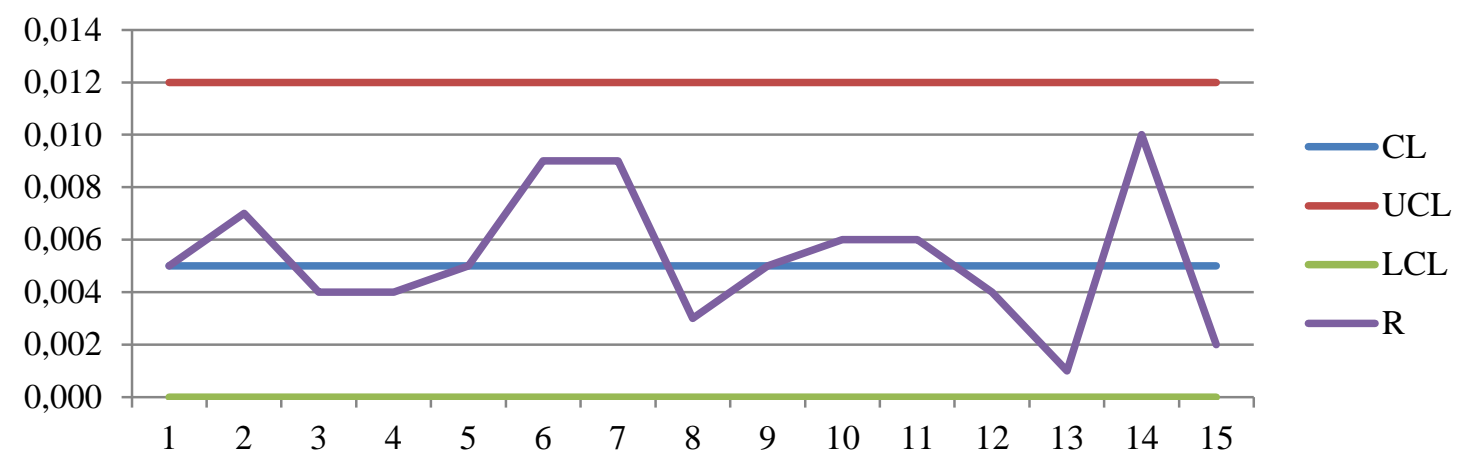

Gambar 8. Grafik Pengamatan R Pada FFA Olein Setelah Dilakukan Revisi Sumber: Penelitian 2021

Grafik Pengamatan Peta $\bar{X}$ FFA Pada Stearin sebelum dan sesudah dilakukan peta revisi dapat dilihat pada Gambar 9 dan 10.

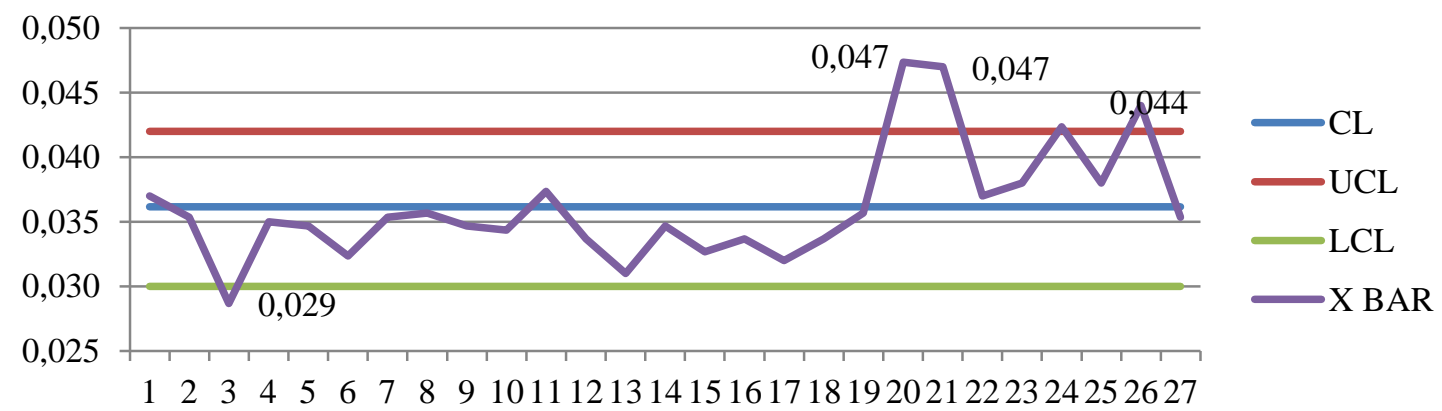

Gambar 9. Grafik Pengamatan X Pada FFA Stearin Sebelum Dilakukan Revisi Sumber: Penelitian 2021 


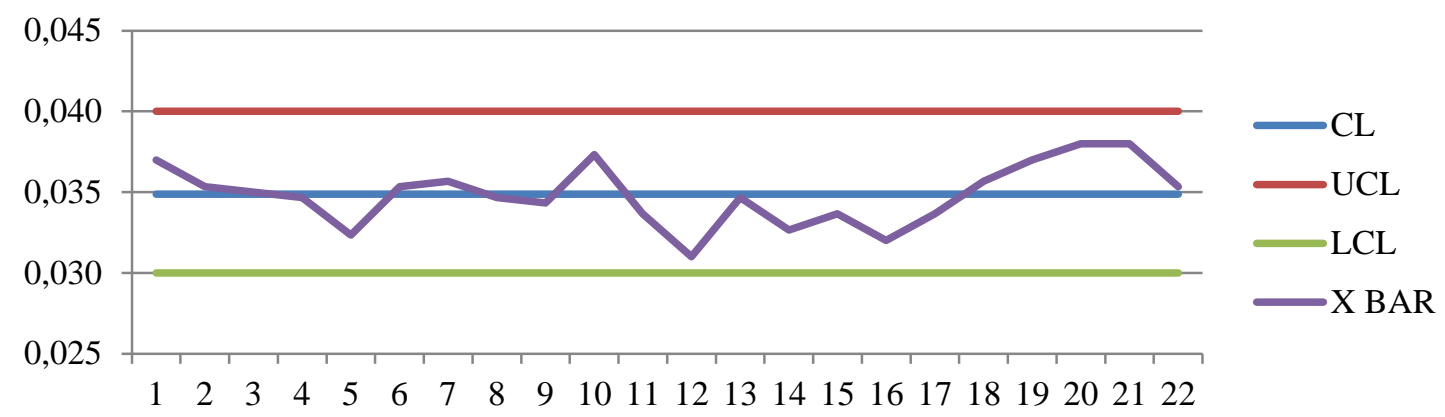

Gambar 10. Grafik Pengamatan X Pada FFA Stearin Setelah Dilakukan Revisi

Sumber: Penelitian 2021

Grafik Pengamatan Peta R FFA Pada Stearin sebelum dan sesudah dilakukan peta revisi dapat dilihat pada Gambar 11 dan 12.

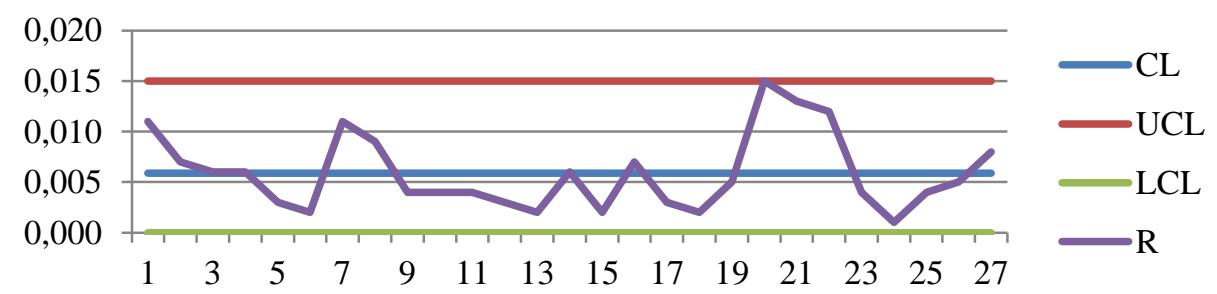

Gambar 11. Grafik Pengamatan Peta R Pada FFA Stearin Sebelum Dıакикаn Revisi Sumber: Penelitian 2021

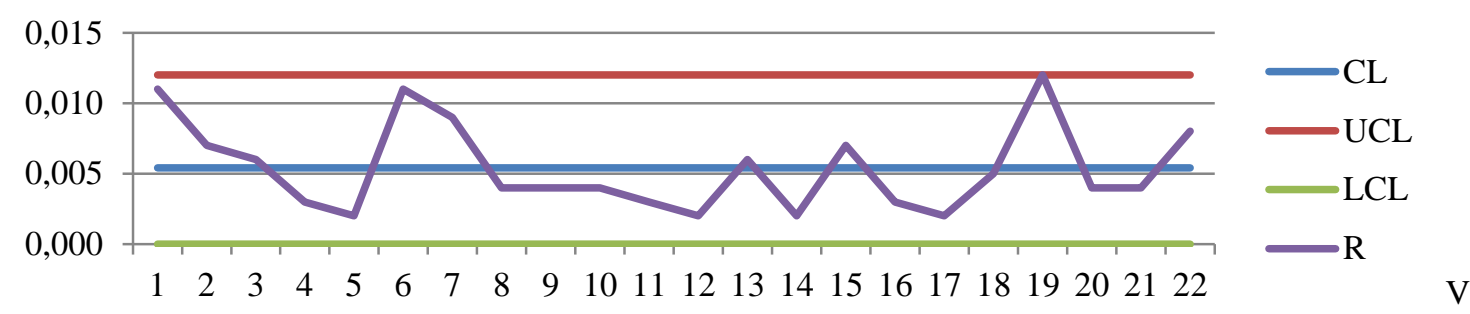

Gambar 12. Grafik Pengamatan Peta R Pada FFA Stearin Setelah Dilakukan Revisı Sumber: Penelitian 2021

\section{Kesimpulan}

Hasil dari penelitian dengan menggunakan metode $\bar{X}$ dan $\mathrm{R}$ semua sampel RBDPO, Olein dan Stearin berada dalam batas peta kendali setelah dilakukan peta revisi sebanyak 3 kali untuk RBDPO dan Olein, 2 kali untuk produk Stearin dengan jumlah sampel yang berbeda-beda. Dimana untuk sampel RBDPO sebelum dilakuka revisi untuk nilai $\overline{\mathrm{X}}$ terdapat 5 sampel yang berada diluar batas peta kendali dan nilai $\mathrm{R}$ terdapat 4 sampel yang berada diluar batas peta kendali, setelah dilakukan peta revisi tahap 3 produk RBDPO untuk $\overline{\mathrm{X}}$ dan $\mathrm{R}$ sudah dalah batas peta kendali dengan jumlah sampel 12 hari. Untuk produk Olein sebelum dilakukan peta revisi untuk $\overline{\mathrm{X}}$ terdapat 6 sampel dan $\mathrm{R}$ terdapat 2 sampel yang diluar batas peta kendali setelah dilakuka peta revisi ketida semua sampel Olein berada dalam batas kendali dengan jumlah sampel 15 hari dan untuk Stearin sebelum dilakukan revisi nilai $\bar{X}$ terdapat 4 sampel yang berada 
diluar batas peta kendali setelah dilakukan peta revisi $\overline{\mathrm{X}}$ dan $\mathrm{R}$ produk Stearin berada dalam batas peta kendali dengan jumlah sampel 22 hari.

\section{Daftar Pustaka}

Arini, W., 1999, Manajemen Kualitas, Yogyakarta

Irwan., Haryono, D., 2015, Pengendalian Kualitas Statistik, Alfabeta, Bandung

Fajar, W.M., dan Wulan., 2014., Analisis pengendalian mutu CPO pada PT Buana Wira Subur Sakti di kabupaten Paser : Universitas Mula Warman: Fakultas Teknik, ISSN 2355-5408, Vol. 2, No. 2

Habibi., 2011, Analisi mutu CPO (Crude Palm Oil) di pabrik kelapa sawit PT. XYZ.

Nasution., Dewi, A., dan Rizky., 2014, Pengendalian kualitas minyak menggunakan metode T-square; Fakulatas Ekonomi, vol.4.

Prawiro,. Novira., dan Nurliza., Analisis pengendalian kualitas mutu CPO menggunakan six sigma di pabrik pengolahan CPO PT Gunajaya Karya Gemilang kecamatan Kendawangan kabupaten Ketapang : Universitas Tanjungpura Pontianak, Fakultas Pertanian, Vol. 05, No. 02 ; 2016

Syarif, M., Pengendalian kualitas dengan metode stastitical quality control (SQC) untuk meminimukan pada toko roti barokah bakery ; Universitas UPM Probolinggo ; Vol. 7, Maret 2017.

Santoso, E., dan Fitri, F., Penerapan Metode SQC Untuk Meningkatkan Kualitas Proses Assembly SIDM Di PT IEI : Peneliti BPT: Staf Produksi Elekronik Industri, ISSN 103-104, Vol. 11, No. 2: 2010

Windarti, T., 2014, Pengendalian kualitas untuk meminimasi produk cacat pada proses produksi besi beton; Vol. 9, No. 3 